\title{
Nursing Students' Challenges and Experiences of Undergoing Clinical Rotation Program during Coronavirus Disease 2019 Pandemic
}

\author{
Bayu Fandhi Achmad*, Sutono Sutono, Sri Setiyarini, Happy Indah Kusumawati, Syahirul Alim
}

Department of Basic and Emergency Nursing, Faculty of Medicine, Public Health and Nursing, Universitas Gadjah Mada, Yogyakarta, Indonesia

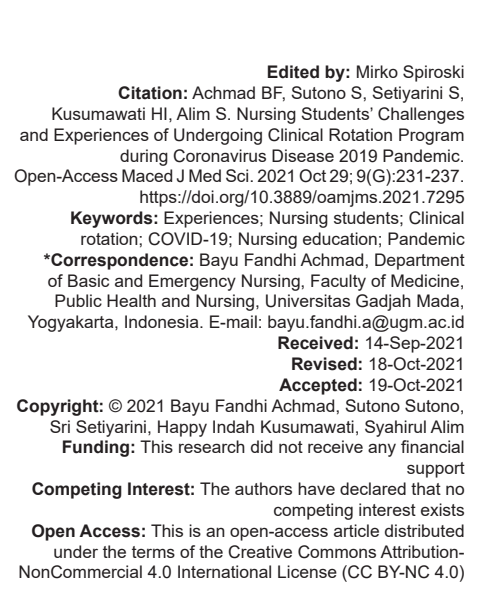

Introduction

The coronavirus disease 2019 (COVID-19) pandemic has seriously affected almost every aspect of life. It has been recently reported that they have infected 192 million people worldwide with over 4.13 million deaths recorded. Indonesia has become the country with the most cases in Southeast Asia and is ranked $20^{\text {th }}$ globally, having nearly 3 million positive cases and more than 77,583 casualties [1]. The rapid increase of the COVID-19 prevalence has threatened the health of doctors, nurses, and even nursing students who are undergoing their clinical rotation programs in hospitals [2].

In Indonesia, several nursing schools have issued policies to facilitate the continuation of clinical rotation education in the hospitals by providing optimum supervision, health protocol socialization, and adequate personal protective equipment (PPE) [3]. This pandemic situation is seen as a valuable opportunity for improving clinical rotation program quality in the future, facilitating the competencies which have been determined essential, and providing valuable clinical experiences for the nursing and medical students [4].

The existence of this policy invites a wide variety of responses from the students who have been directly involved in inpatient treatment in hospitals [5]. Different from competent and experienced nurses, nursing students need to prepare themselves in the best way possible regarding the potential challenges and stress [6]. The lack of information and knowledge regarding epidemiological concepts related to the COVID-19 disease and transmission mechanism, both whether it is in the community level or hospital setting, has ignited anxiety responses for students [7].

The description above shows that there are many issues faced by nursing students to undergo training in nursing care during the COVID-19 pandemic. Accordingly, this study aimed to explore the challenges and experiences of nursing students who undergo their clinical rotation during the COVID-19 pandemic. This study's finding will help the clinical instructors evaluate the quality of nursing care, the challenges, and the obstacles faced by students. Data collected will provide the educational institutions important empirical 
evidence to consider the effects of their academic policy for the clinical rotation programs during the COVID-19 pandemic.

\section{Materials and Methods}

\section{Design and setting}

This study used a qualitative content analysis approach using an interpretive model to investigate nursing students' challenges and experiences undergoing clinical rotation programs during the COVID-19 pandemic. As a research method, the content analysis represents a systematic and objective means of describing and quantifying phenomena [8]. Furthermore, it accommodates direct insights into correlated experiences with qualitative research [9]. It was considered appropriate for this qualitative research.

\section{Participants}

The participants were purposefully chosen using criteria. The participant that is eligible for the inclusion criteria is a nursing student who completed 4 weeks clinical rotation in a hospital. Thus, criteria were chosen because the participants had experienced many nursing competencies. The number of clinical experiences received by students is assumed to be with more diverse experiences that participants feel while undergoing clinical rotation [10].

In contrast to students who have just entered the clinical rotation, students who have completed the intensive care unit (ICU) and intensive cardiovascular care unit stage are given more authority to perform nursing care. Moreover, students who were not willing to participate were excluded from this study. At initial contact, participants were informed about the process of the study. To obtain participants' perceptions about the clinical rotation nursing program during the COVID19 pandemic, we conducted a focus group discussion (FGD). Before the data collection, online informed consent was obtained from participants.

We achieved data saturation for the $28^{\text {th }}$ participant. To ensure that the data were completely saturated, we added 3 more (10\%) students. So that the total participants involved in this study were 31 students. The data saturation is determined by the researcher [11]. The 31 participants' age ranged from 23 to 25 years, and all of them were female. Their clinical rotation stage is typical.

\section{Data collection}

FGDs were conducted to explore nursing students' experiences of clinical rotation through their thoughts, perceptions, expectations, and stories during the COVID-19 pandemic. FGD is perceived to be a "cost effective" and "promising alternative" in participatory research [12]. The FGD itself was divided into four groups, at each group consists of seven participants. The grouping of participants was carried out by the researcher. In addition, the three other participants were being interviewed separately from the prior group.

All FGD lasted for an average of 90-120 min. All FGDs were established from the residing home of each participant. Each small group was given information about the research data collection process that was undertaken through Google Forms. The researcher collected data using a Zoom conference application in each group once. Because there are four groups, the zoom conference was held 4 times. Researchers used interview guidelines when collecting data from participants. In collecting data, the researcher ensures that the data are saturated [13].

A semi-structured topic guide, inspired by the literature and feedback from the Clinical Instructor, was developed. The discussion begins with a general question that explores students' perceptions about the clinical rotation nursing program during the COVID19 pandemic, their feelings and thoughts on the academic policy, and their hopes about the program. The interviewer used the guided topic as guidance and developed another topic if necessary, depends on the participants' response [14].

Field notes were prepared by the researcher as backup data only because all Zoom conference activities with participants had been recorded (both video and audio) with the participants' permission. The FGDs were conducted by researchers in Bahasa Indonesia and transcribed verbatim. These transcripts then being reviewed by the team member to guarantee the consistency and accuracy of the translation [15].

\section{Data analysis}

Within $24 \mathrm{~h}$ of each interview, the recording was transcribed verbatim and analyzed using the content analysis method which includes five main segments: Familiarization, coding, theme creation, thematic description, and reporting [16], [17], [18]. Three researchers independently reviewed the interview materials. To obtain a better understanding of the results, the transcribed interview was read many times. Then, the data were analyzed line by line to emerge the code [15]. In this study, all of the meaningful statements were being extracted and labeled with symbols, forming ratification substantial.

The third stage involved formulating the present themes. Conflicting opinions on the contents of a theme were discussed and resolved by a team 
member composed of three Master of Nursing and two Doctor of Nursing. The code abstracted in the prior stage was sorted into corresponding subcategories and categories [19] (Table 1).

Dependability was achieved by having expert qualitative nursing researchers review the transcribed material to validate the themes and descriptors identified [20]. Confirmability was met by maintaining a reflexive journal during the research process to keep notes and document introspections daily that would be beneficial and pertinent to the study. An audit trail also took place to examine the processes whereby data were collected and analyzed, and interpretations were made. The audit trail took the form of documentation (the actual interview notes taken) and a running account of the process [21].

Credibility was conducted by not only debriefing data but also member checking during the data collection process. Furthermore, bracketing was conducted to separate the assumptions and biases from the essences and therefore understands the phenomenon as experienced by the participants of the study. The collected and analyzed data were presented to the participants, and they were asked whether the narrative is accurate and an accurate reflection of their experience. Our interpretation and descriptions of the narratives were presented to the participants to achieve credibility [18]. They could review the transcripts and change them if they wished to do so.

Transferability was enhanced using the purposive sampling method and providing a thick description and robust data with a wide range of information through the detailed descriptions of the participants. In this study, recruitment of participants and data collection continued until the data are saturated [20].

\section{Results}

Four major themes were gained after reviewing the participants' FGD results. The four major themes were: (1) The negative emotions in the initial stage; (2) the positive emotions; (3) the competency that was difficult to achieve, and (4) strategies for coping and self-care. The themes that emerged from the study were collected based on students' experiences and challenges of undergoing clinical rotation during COVID-19 pandemics.

\section{Theme 1: The negative emotions}

All participants expressed feelings of negative emotions when they acknowledged they would undergo clinical practice in the hospital during the COVID-19 pandemic.

“...Actually, I felt afraid on the $1^{\text {st }}$ time I went for working, because I heard a news (or issue) that there were COVID-19 patients who were mis-screened so that they were being taken care of in a non-COVID-19 ward..." (P28)

“...So, my initial feeling when for the $1^{\text {st }}$ time that I will be back (to the hospital), in the beginning I was afraid and my heart pounded fast because it was during everyone talks about the pandemic and mass media is still so strong reporting about COVID-19, and of course, the public fear is so high. I was also afraid of getting infected, because I have comorbid disease..." (P9)

“...What I felt was anxious and insecure because I heard from a friend that there were COVID-19 patients who had passed screening so that they were being taken care of in the non-COVID-19 ICU, so I was afraid to undergo nursing education in the ICU..." (P26)

Table 1: Results of interviews content analysis including general theme, themes, and subthemes of nursing students

\begin{tabular}{|c|c|c|}
\hline Theme & Subtheme & Example of participants' answer \\
\hline $\begin{array}{l}\text { The negative } \\
\text { emotion }\end{array}$ & $\begin{array}{l}\text { - Fear of COVID-19 infection } \\
\text { - Anxiety due to environmental } \\
\text { changes } \\
\text { - Anxiety about exposing the virus to } \\
\text { their family }\end{array}$ & $\begin{array}{l}\text { "...Actually, I felt afraid on the } 1^{\text {st }} \text { time I went for working, because I heard a news (or issue) that there were COVID-19 patients } \\
\text { who were mis-screened so that they were being taken care of in a non-COVID-19 ward..." (P28) } \\
\text { "....So, my initial feeling when for the } 1^{\text {st }} \text { time that I will be back (to the hospital), in the beginning I was afraid and my heart pounded } \\
\text { fast because it was during everyone talks about the pandemic and mass media is still so strong reporting about COVID-19, and } \\
\text { of course the public fear is so high. I was also afraid of getting infected, because I have comorbid disease..." (P9) } \\
\text { "...What I felt was anxious and insecure because I heard from a friend that there were COVID-19 patients who had passed } \\
\text { screening so that they were being taken care of in the non-COVID-19 ICU, so I was afraid to undergo nursing education in } \\
\text { the ICU..." (P26) } \\
\text { "...Besides that, I feel anxious because whenever I get home, I will transmit COVID-19 to my family members..." (P10) }\end{array}$ \\
\hline $\begin{array}{l}\text { The positive } \\
\text { emotion }\end{array}$ & $\begin{array}{l}\text { - Motivation to gain clinical } \\
\text { experiences } \\
\text { - Self-efficacy to face the challenges } \\
\text { - Motivation to graduate } \\
\text { - Peacefulness }\end{array}$ & $\begin{array}{l}\text { “... Honestly, I feel so glad, because in my humble opinion, it is such an opportunity to undergo clinical education in the course } \\
\text { of a pandemic like nowadays and this will be a valuable experience..." (P15) } \\
\text { “...After I entered clinical education (in ER), I felt that in real life, it wasn't as horrifying as what I had imagined before. A healthcare } \\
\text { worker in ER is indeed wearing PPE according to the health protocol, but it doesn't make a horrifying impression to me..." (P2) } \\
\text { “...For me personally, when I have the chance to undergo clinical education in the hospital (ER), I feel glad, because I will try } \\
\text { implementing clinical skills directly and have valuable clinical experiences, even though it still needs protection protocol to } \\
\text { prevent the exposure of the virus..." (P18) }\end{array}$ \\
\hline $\begin{array}{l}\text { The competency } \\
\text { that is difficult to } \\
\text { achieve }\end{array}$ & $\begin{array}{l}\text { - CPR procedure } \\
\text { - High-risk procedures (nebulizer and } \\
\text { phlebotomy) }\end{array}$ & $\begin{array}{l}\text { "...I think its CPR, because CPR produces aerosol and there is an extra Standard Operation Procedure, so I am still in doubts } \\
\text { about doing CPR with PPE that I wear..." (P21) } \\
\text { "....Due to COVID-19 pandemic, we are not suggested to do nebulizer because it is considered as causing aerosol..." (P14) } \\
\text { "...For me, skill that is the hardest to carry out when we are wearing PPE is blood sampling, because the foggy face shield and } \\
\text { it disturbs our vision when we are doing needle insertion..." (P23) }\end{array}$ \\
\hline Coping strategies & $\begin{array}{l}\text { - Active or passive coping } \\
\text { - Physical coping strategies } \\
\text { - Support system } \\
\text { - Cognitive coping strategies }\end{array}$ & $\begin{array}{l}\text { "...Coping that I apply to myself is by doing more religious activities and praying, so that I will be blessed with psychological } \\
\text { calmness and safety during my clinical education..." (P9) } \\
\text { "...For me, I usually have a chat with my friends for sharing..." (P29) } \\
\text { "...I always have a mindset that the PPE I wear is according to the standard and safe to treat patients..." (P6) }\end{array}$ \\
\hline
\end{tabular}


"...Besides that, I feel anxious because whenever I get home, I will transmit COVID-19 to my family members..." (P10).

\section{Theme 2: The positive emotions}

With the negative emotions, positive emotions were felt by the participants as well. Alongside the feelings of nervousness and anxiousness, the participants were also motivated to gain nursing education experiences during the COVID-19 pandemic.

“...Honestly, I feel so glad, because in my humble opinion, it is such an opportunity to undergo clinical education in the course of a pandemic like nowadays and this will be a valuable experience..." (P15)

“...After I entered clinical education (in ER), I felt that in real life, it wasn't as horrifying as what I had imagined before. A health care worker in ER is indeed wearing PPE according to the health protocol, but it doesn't make a horrifying impression to me..." (P2)

“...For me personally, when I have the chance to undergo clinical education in the hospital (ER), I feel glad, because I will try implementing clinical skills directly and have valuable clinical experiences, even though it still needs protection protocol to prevent the exposure of the virus..." (P18).

\section{to achieve \\ Theme 3: The competency that is difficult}

There were several competencies in which the nursing students felt that they had not optimally achieved, namely, skills which have high potential in exposing them to COVID-19 transmission.

“...I think it's CPR, because CPR produces aerosol and there is an extra Standard Operation Procedure, so I am still in doubts about doing CPR with PPE that I wear..." (P21)

"...Due to COVID-19 pandemic, we are not suggested to do nebulizer because it is considered as causing aerosol..." (P14)

"...For me, a skill that is the hardest to carry out when we are wearing PPE is blood sampling, because the foggy face shield and it disturbs our vision when we are doing needle insertion..." (P23).

\section{Theme 4: Coping strategies}

By the emergence of positive or negative emotions, each participant of this study had different ways of coping and reducing stress before the clinical rotation program. The coping strategy which was implemented by each of them was by performing the psychological adjustment.

"...Coping that I apply to myself is by doing more religious activities and praying, so that I will be blessed with psychological calmness and safety during my clinical education..." (P9)

“...For me, I usually have a chat with my friends for sharing." (P29)

"...I always have a mindset that the PPE I wear is according to the standard and safe to treat patients..." (P6).

\section{Discussion}

Ever since the COVID-19 pandemic started, clinical education in hospitals has become a challenging issue for nursing students in Indonesia. Based on the research results, it can be acknowledged that emotional experiences endured by most of the participants are the feelings of anxiety and fear of undergoing a clinical rotation program during the COVID-19 pandemic [22]. The clinical rotation program has become one of the transitional stages from academic to clinical education, where student knowledge is being implemented directly to the patients in the hospitals [6]. For several students, this very transitional stage is considered a very challenging and quite difficult stage [23]. In the current COVID-19 pandemic, the clinical rotation program produces various kinds of stressors for the students [8]. Participants experienced fear due to the escalation of the number of COVID-19 cases. Its prevalence continues to increase with little reduction in Indonesia [1].

The COVID-19 pandemic contributes to a new point of view for nursing students, where the students are facing two dilemmas in the current conditions, which are prioritizing personal safety and family security or focusing upon patients' safety [24]. Negative emotions endured by the participants are based on the occurrence of a sense of fear about the potential of COVID-19 transmission while undergoing the clinical rotation program [25]. There is an assumption of clinical rotation program students in the hospitals that they have become a population vulnerable to be highly exposed to COVID-19 [26]. Furthermore, the assumption is in line with the participants' thoughts of this study which is the view of hospitals as the COVID-19 virus incubator with a significantly higher virus transmission potential compared to the public sphere.

COVID-19 is a virus that can infect with soaring high virulence caused by the severe acute respiratory syndrome coronavirus 2 [27]. Meanwhile, the existence of asymptomatic patients with COVID-19 becomes a specific concern, since at the stage when the patients are asymptomatic, they are not aware that they have been infected with the virus and can potentially transmit to others in their surroundings, especially when they do not implement the appropriate health protocol [28]. In 
addition to this asymptomatic COVID-19 phenomenon, there is an ongoing stigma amongst the people of Indonesia that is directed toward a person when someone gets infected with COVID-19, hence, this infected individual will be alienated and the people around this person will not embrace the person who has been confirmed as COVID-19 positive [29]. As a result, many suspected patients choose to manipulate their symptoms or important data which are used as the basis of COVID-19 diagnosis. Moreover, the heightened sense of anxiety occurs concerning that the students may transmit the virus to their family members after undergoing a clinical rotation program which is included as one of the negative emotions felt by the participants [30].

Not only do participants endure the negative emotions but they also experience positive emotions. The participants assume that in the real-time situation in the hospitals, there are many supports given by their surroundings; hence, the participants feel safe and secure in undergoing their clinical rotation program. In this case, the sense of fear in the initial stage of undergoing a clinical rotation program can be overcome effectively by the participants [31].

The individuals rely on several parts of their psychological aspects in accessing their anxiety and the conditions with a high level of stress. The reaction of fear felt by the participants has initiated them to build anticipatory self-arousal situations which then can reduce the sense of fear in which these individuals experienced, or commonly called psychological and emotional states based on irrational, anticipatory anxiety [24]. Furthermore, the participants of the study are motivated to gain nursing education experiences in the real environment, which is in the hospitals, since they will achieve better competency goals there than only by undergoing virtual learning. In addition, the supports from the clinical instructor can increase the level of readiness among the participants before undergoing their clinical rotation program [3]. The readiness of undergoing the daily real-life practice is based on the participants' urge and motivation to graduate as professional nurses, thus this clinical rotation program stage must be undertaken [8].

However, several treatments are difficult to be implemented, for instance, basic life support, nebulizer, and phlebotomy. Basic life support is one of the basic skills of nursing students which must be trained in a real setting to achieve the expected competency level [32]. Having a variety of health risks during the pandemic, the participants implement several adjustments through their coping strategies and self-care [33].

Some of the participants implement coping strategies through either active or passive coping to overcome the stressors. The stress experienced by the students during nursing education is due to the discrepancy between their expectations and the practical conditions in the real setting [34]. For instance, there are the practical demands with high-intensity workloads, efforts to achieve competency, and selfadaption regarding regulations and norms which are implemented in the workplaces. Coping mechanisms are also implemented by the students to adapt to the workplace culture. Students having high resilience and low burnout level are easier to implement coping mechanisms employing self-regulation strategies [35]. On the contrary, students having low resilience and high burnout level tend to experience self-blame [34].

Several coping mechanisms have been implemented by the participants of this study, namely, engaging in positive activities, doing their hobbies, having interactions with their friends, and getting social supports from their colleagues, improving their religious worship quality, and praying, implementing a positive mindset, as well as staying fit. Moreover, the participants ask for their family support since it is considered as one of the major support systems experienced by the participants. The results of the study show that for health care workers in Indonesia, family support becomes the main factor that can increase the motivation of the health care workers in conducting optimum nursing care during the COVID-19 pandemic [36].

The results also showed that one of the participants' coping strategies was to adjust their perceptions. Participants can instill confidence that their PPE can protect them from exposure to the virus [37]. However, this positive belief must be accompanied by adherence to health protocols in handling COVID-19. Furthermore, there must be a guarantee from the institution regarding the availability of PPE that can be used by the students [38]. Students feel that the institutions must be responsible to check whether students have adequate protection [39].

We chose to develop research that was able to explore the challenges and experiences of nursing students in undergoing a clinical rotation during the COVID-19 pandemic because this is a new topic and has never been explored before. Other research could extend our approach to exploring the challenges and experiences not only among the nursing students but also the clinical instructors or other medical professionals. Furthermore, based on the results of this study, educational institutions can consider curriculum policies related to the target competency attainment that nursing students must achieve during a pandemic because of the many competencies that are difficult to achieve [40].

\section{Conclusion}

In general, this study describes the occurrence of negative and positive emotions experienced by nursing students during the implementation of their clinical rotation program. Positive emotions can 
be attained due to their coping strategies and the self-care implemented by the students. Therefore, the students can overcome many of the challenges during the pandemic. Nursing students also experience several obstacles in achieving competency due to the inadequate guidance process during the pandemic and limited access to remedial actions that students can take. This study provided fundamental data for further research concerning these important topics.

\section{References}

1. World Health Organization. Coronavirus Disease (COVID-19) in Indonesia. Geneva: World Health Organization; 2020. Available from: https://covid19.who.int/region/searo/country/id. [Last accessed on 2021 Jun 21].

2. World Health Organization. Keep Health Worker Safe to Keep Patients Safe. Geneva: World Health Organization; 2020. Available from: https://www.who.int/news/item/17-09-2020keep-health-workers-safe-to-keep-patients-safe-who

3. Swift A, Banks L, Baleswaran A, Cooke N, Little C, McGrath L. COVID-19 and student nurses: A view from England. J Clin Nurs. 2020;29(17-18):1-4. http://doi.org/10.1111/jocn.15298 PMid:32298512

4. Harries AJ, Lee C, Jones L, Rodriguez RM, Davis JA, BoysenOsborn M, et al. Effects of the COVID-19 pandemic on medical students: A multicenter quantitative study. BMC Med Educ. 2021;21(14):1-8. http://doi.org/10.1186/s12909-020-02462-1

5. Albaqawi $\mathrm{HM}$, Alquwez $\mathrm{N}$, Balay-Odao $\mathrm{E}$, Bajet JB, Alabdulaziz H, Alsolami F, et al. Nursing students' perceptions, knowledge, and preventive behaviors toward COVID-19: A multi-university study. Front Public Health. 2020;8:573390. http://doi.org/10.3389/fpubh.2020.573390 PMid:33425830

6. Safan SM, Ebrahim RM. Problems and obstacles facing nursing interns and its relation to their performance at clinical setting: A comparative study. Am J Nurs Sci. 2018;7(6):304-13. http:// doi.org/10.11648/j.ajns.20180706.24

7. Cervera-Gasch Á, González-Chordá V, Mena-Tudela D. COVID-19: Are Spanish medicine and nursing students prepared? Nurse Educ Today. 2020;92:104473. http://doi. org/10.1016/j.nedt.2020.104473

PMid:32497867

8. Gómez-lbáñez R, Watson $\mathrm{C}$, Leyva-Moral J, AguayoGonzález M, Granel N. Final-year nursing students called to work: Experiences of a rushed labour insertion during the COVID-19 pandemic. Nurse Educ Pract. 2020;49:102920. http://doi.org/10.1016/j.nepr.2020.102920

PMid:33217641

9. Elo $S$, Kääriäinen $M$, Kanste $O$, Pölkki $T$, Utriainen $K$, Kyngäs $H$. Qualitative content analysis: A focus on trustworthiness. Sage Open. 2014;2014:1-10. http://doi. org/10.1177/2158244014522633

10. Chow SK, Wong LT, Chan YK, Chung TY. The impact and importance of clinical learning experience in supporting nursing students in end-of-life care: Cluster analysis. Nurs Educ Pract. 2014;14(5):532-7. http://doi.org/10.1016/j.nepr.2014.05.006 PMid:24916407

11. Guest G, Namey E, Chen M. A simple method to assess and report thematic saturation in qualitative research. PLoS One. 2020;15(5):e0232076. http://doi.org/10.1371/journal. pone.0232076

PMid:32369511

12. Nyumba TO, Wilson K, Derrick, CJ, Mukherjee N. The use of focus group discussion methodology: Insights from two decades of application in conservation. Methods Ecol Evol. 2018;9:20-32. http://doi.org/10.1111/2041-210X.12860

13. Creswell JW, Fetters MD, Ivankova NV. Designing a mixed methods study in primary care. Ann Fam Med. 2004;2(1):7-12. http://doi.org/10.1370/afm.104 PMid: 15053277

14. Dos Santos Marques IC, Theiss LM, Johnson CY, McLin E, Ruf BA, Vickers SM, et al. Implementation of virtual focus groups for qualitative data collection in a global pandemic. Am J Surg. 2021;221(5):918-22. http://doi.org/10.1016/j. amjsurg.2020.10.009 PMid:33070983

15. Vaismoradi, M. Snelgrove S. Theme in qualitative content analysis and thematic analysis. Forum Qual Sozialforsch. 2019;20(3):3376. http://doi.org/10.17169/fqs-20.3.3376

16. Bryman A, Burgess B. Analyzing Qualitative Data. London, United Kingdom: Routledge; 2002. http://doi.org/10.31983/jrk. v8i1.3918

17. Braun V, Clarke V. Using thematic analysis in psychology. Qual Res Psychol. 2006;3:77-101. http://doi. org/10.1191/1478088706qp063oa

18. Flick U. An Introduction to Qualitative Research. United States: Sage Publications Limited; 2018.

19. Ritchie J, Lewis J, Nicholls CM, Ormston R. Qualitative Research Practice: A Guide for Social Science Students and Researchers. United States: SAGE; 2013.

20. Forero R, Nahidi S, De Costa J, Mohsin M, Fitzgerald G, Gibson N, et al. Application of four-dimension criteria to assess rigour of qualitative research in emergency medicine. BMC Health Serv Res. 2018;18:120. http://doi.org/10.1186/ s12913-018-2915-2

21. Carcary M. The research audit trail: Methodological guidance for application in practice. Electron $\mathrm{J}$ Bus Res Methods. 2020;18(2):1-8. http://doi.org/10.34190/JBRM.18.2.008

22. Temiz Z. Nursing students' anxiety levels and coping strategies during the COVID-19 pandemic. Int Arch Nurs Health Care. 2020;6:150. http://doi.org/10.23937/2469-5823/1510150

23. García-González J, Ruqiong W, Alarcon-Rodriguez R, RequenaMullor M, Ding C, Ventura-Miranda MI. Analysis of anxiety levels of nursing students because of e-learning during the COVID-19 pandemic. Health (Basel, Switzerland). 2021;9(3):252. http:// doi.org/10.3390/healthcare9030252

PMid:33804344

24. Eweida RS, Rashwan ZI, Desoky GM, Khonji LM. Mental strain and changes in psychological health hub among internnursing students at pediatric and medical-surgical units amid ambience of COVID-19 pandemic: A comprehensive survey. Nurse Educ Pract. 2020;49:102915. http://doi.org/10.1016/j. nepr.2020.102915

PMid:33227694

25. Huang L, Lei W, Xu F, Liu H, Yu L. Emotional responses and coping strategies in nurses and nursing students during Covid-19 outbreak: A comparative study. PLoS One. 2020;15(8):e0237303. http://doi.org/10.1371/journal. pone. 0237303

PMid:32764825

26. Saddik B, Hussein A, Al-roub NM, Marhoon FA, Hamid Q, Halwani R. Increased levels of anxiety among medical and nonmedical university students during the COVID-19 pandemic in the United Arab Emirates. Risk Manag Healthc Policy. 2020;13:2395-406. http://doi.org/10.2147/rmhp.s273333 


\section{PMid:33177898}

27. Shereen MA, Khan S, Kazmi A, Bashir N, Siddique R COVID-19 infection: Origin, transmission, and characteristics of human coronaviruses. J Adv Res. 2020;24:91-8. http://doi. org/10.1016/j.jare.2020.03.005

28. Centers for Disease Control and Prevention. Clinical Questions about COVID-19: Questions and Answers. 2021. Available from: https://www.cdc.gov/coronavirus/2019-ncov/hcp/faq. html\#Transmission. [Last accessed on 2021 Jun 21].

29. Mastulessy A. Social stigma toward COVID-19 patients in Indonesia; 2020. Available from: https://www.apa.org/ international/global-insights/covid-19-indonesia. [Last accessed on 2021 Jun 21].

30. ThorntonTM, DeckerSA, RoeEA. Fearofcontagionamongnursing students in the era of COVID-19. J Nurs Educ. 2021;60(7):404-7. http://doi.org/10.3928/01484834-20210616-09.

PMid:34232816

31. Gandhi S, Sahu M, Govindan R, Nattala P, Gandhi S, Sudhir PM, et al. Psychological preparedness for pandemic (COVID-19) management: Perceptions of nurses and nursing students in India. PLoS One. 2021;16(8):e0255772. http://doi.org/10.1371/ journal.pone.0255772

PMid:34388177

32. Achmad BF. Effect of cardiopulmonary resuscitation training towards cardiac arrest emergency knowledge upon students at Student Health Association of Universitas Gadjah Mada, Indonesia. Int J Res Med Sci. 2020;8(10):3463. http://doi. org/10.18203/2320-6012.ijrms20204217

33. Ali H, Cole A, Ahmed A, Hamasha S, Panos G. Major stressors and coping strategies of frontline nursing staff during the outbreak of coronavirus disease 2020 (COVID-19) in Alabama. J Multidiscip Healthc. 2020;13:2057-2068. http://doi. org/10.2147/JMDH.S285933

PMid:33408479

34. Ching SS, Cheung K, Hegney D, Rees CS. Stressors and coping of nursing students in clinical placement: A qualitative study contextualizing their resilience and burnout. Nurse education in practice. 2020;42:102690. http://doi.org/10.1016/j. nepr.2019.102690

PMid:31881460

35. Rafati F, Nouhi E, Sabzevari S, Dehghan-Nayeri N. Coping strategies of nursing students for dealing with stress in clinical setting: A qualitative study. Electron Physician. 2017;9(12):6120-8. http://doi.org/10.19082/6120

PMid:29560168

36. Priode KS, Dail RB, Melvin S. Nonacademic factors that influence nontraditional nursing student retention. Nurs Educ Perspect. 2020;41(4):246-8. http://doi.org/10.1097/01. NEP. 0000000000000577

PMid:31609822

37. Neuwirth MM, Mattner F, Otchwemah R. Adherence to personal protective equipment use among healthcare workers caring for confirmed COVID-19 and alleged non-COVID-19 patients. Antimicrob Resist Infect Control 2020;9:199. http://doi. org/10.1186/s13756-020-00864-w

38. Hoedl M, Eglseer D, Bauer S. Associations between personal protective equipment and nursing staff stress during the COVID-19 pandemic. J Nurs Manag. 2021;2021:13400. http://doi.org/10.1111/jonm.13400 PMid:34174009

39. Ulenaers D, Grosemans J, Schrooten W, Bergs J. Clinical placement experience of nursing students during the COVID-19 pandemic: A cross-sectional study. Nurse Educ Today. 2021;99:104746. http://doi.org/10.1016/j.nedt.2021.104746 PMid:33545565

40. Dewart G, Corcoran L, Thirsk L, Petrovic K. Nursing education in a pandemic: Academic challenges in response to COVID-19. Nurse Educ Today. 2020;92:104471. http://doi.org/10.1016/j. nedt.2020.104471

PMid:32502723 